Short Communication

\title{
Processes of Hydrogen Release Relaxation at Thermal Decomposition of Electrodes of Nickel-Cadmium Batteries
}

\author{
Nataliya N. Yazvinskaya, Nikolay E. Galushkin*, Dmitriy N. Galushkin, Inna A. Galushkina \\ Don State Technical University, Laboratory of electrochemical and hydrogen energy, 147 Shevchenko \\ Street, Town of Shakhty, Rostov Region, Russia, 346500. \\ *E-mail: galushkinne@mail.ru
}

doi: $10.20964 / 2017.04 .28$

Received: 13 January 2017 / Accepted: 8 February 2017 / Published: 12 March 2017

In this study, it is shown that processes of hydrogen release relaxation at thermal decomposition of sintered electrodes of nickel-cadmium batteries are conditioned by the combination of the following factors. Firstly, this is the distribution of atomic hydrogen all around the entire volume of a ceramicmetal matrix of an electrode. Secondly, this is the very low diffusion coefficient of the atomic hydrogen in ceramic-metal matrices, which is connected with the fact that inside of the ceramic-metal matrix of the electrode, the atomic hydrogen is found in its bound state ( $\beta$-phase). Thirdly, this is a large concentration of the atomic hydrogen in the ceramic-metal matrix of the porous electrode: the atomic hydrogen is accumulated in such electrodes in a course of batteries long-term operation.

Keywords: relaxation, hydrogen accumulation, thermal runaway, battery, nickel-cadmium

\section{$\underline{\text { FULL TEXT }}$}

(C) 2017 The Authors. Published by ESG (www.electrochemsci.org). This article is an open access article distributed under the terms and conditions of the Creative Commons Attribution license (http://creativecommons.org/licenses/by/4.0/). 